\section{COVID-19 and renal disease in elderly patients}

\author{
Giuseppe Coppolino, ${ }^{1}$ \\ Pierangela Presta, ${ }^{1}$ Ramona Nicotera, ${ }^{1}$ \\ Giordano Placida, ${ }^{1}$ Caterina Vita, ${ }^{1}$ \\ Nazareno Carullo, ${ }^{1}$ Michele Andreucci, ${ }^{1}$ \\ Davide Bolignano, ${ }^{1}$ Alberto Castagna, ${ }^{2}$ \\ Giovanni Ruotolo \\ ${ }^{1}$ Renal Unit, Magna Graecia University, \\ Catanzaro; ${ }^{2}$ Center for Cognitive \\ Disorders and Dementia, DSS \\ Catanzaro, ASP Catanzaro; ${ }^{3}$ Geriatric \\ Unit, Pugliese-Ciaccio Hospital of \\ Catanzaro, Italy
}

\begin{abstract}
The pandemic blast of COVID-19 uncovered well known weakness of financial chain and put our economic organizations facing off dramatic consequences if new strategies will not be developed to adapt health-care on detailed sub-groups of patients. The exponential number of older and frail subjects aged $>65$ years represents a challenge for public health. Patients affected by renal disease are an aged population that showed a particular attitude to contract infection and a higher mortality rate respect to general population. In this brief article, we would point out the focus on the management of issues related to renal patients facing off with coronavirus infection, in particular in a geriatric population particularly exposed to contagion like hemodialysis patients and precautions decided to slow the spread of contamination.
\end{abstract}

\section{Introduction}

The exponential number of older and frail subjects aged $>65$ years represents a challenge for public health. The pandemic blast of COVID-19 uncovered well known weakness of financial chain and put our economic organizations facing off dramatic consequences if new strategies will not be developed to adapt health-care on detailed sub-groups of patients. ${ }^{1}$ In few months an avalanche overwhelmed in an unexpected way our existences even if the warning growl for a possible pandemic occurrence recently arrived in 2003 with severe acute respiratory syndrome (SARS). It represented the first global threat of the $21^{\text {st }}$ century and spontaneously disappearing in June 2003. The novel coronavirus instead was identified in December 2019 as the agent responsible for some cases of pneumonia in Wuhan, Hubei Province, China. ${ }^{2}$ On February 2020, the World Health Organization (WHO) named the disease caused by the new coronavirus COVID-19 (Coronavirus Disease 2019). ${ }^{3}$ The number of infections has increased dramatically first in China and then in other countries around the world, so much so that in March 2020 the WHO declared a pandemic. The peak of contagion in China was reached between the end of January 2020 and the beginning of February 2020 with more than 80,000 cases. ${ }^{4}$ Immediately after China, South Korea, Italy, Iran and Japan and, at a later time, also Spain, France, Germany, the United Kingdom and the United States also presented an increase in the number of infections. Mortality is estimated at $2-3 \%$ in critical cases..$^{5-7}$ In Italy at the date of April 13,2020 , the overall case-fatality rate was 7 -fold higher than in other counties but it is probably due to a highly underestimated number of infections. Recent data from the Italian Istituto Superiore di Sanità showed that COVID-19 is more lethal in older subjects: the $96.4 \%$ of died patients had more than 60 years. When data were stratified by age groups, individuals aged 70 years or older represent $35.5 \%$ of cases while subjects aged $\geq 80$ years were $52.3 \%{ }^{8}$

Patients affected by renal disease are an aged population that showed a particular attitude to contract infection and a higher mortality rate respect to general population. In this brief article, we would point out the focus on the management of issues related to renal patients facing off with coronavirus infection, in particular in a geriatric population particularly exposed to contagion like hemodialysis patients and precautions decided to slow the spread of contamination.

\section{Chronic kidney disease patients and COVID-19}

Since most chronic renal patients are elderly as consequence of physiologic decline of renal function and higher susceptibility to renal diseases, ${ }^{9}$ the COVID-19 is a relevant problem in chronic renal patients for its increased risk of complications and mortality. Furthermore, the use of some antiviral and immunosuppressive therapies to fight COVID-19 infection is complicated by kidney damage with acute kidney injury. The age and the chronic renal pathology together are probably a risk factor for COVID-19 for the immunosuppressive status. Immunosenescence is known in elderly and it is characterized by an impaired function of both,
Correspondence: Alberto Castagna, Center for Cognitive Disorders and Dementia DSS Catanzaro, Azienda Sanitaria Provinciale di Catanzaro, viale Crotone, 88100 Catanzaro, Italy.

Tel./Fax: +39.096.17033013.

E-mail: albertocastagna@tiscali.it

Key words: COVID-19; elderly; renal patients.

Contributions: GC, PP, RN, GP, CV, NC, DB, $\mathrm{AC}, \mathrm{GR}$, literature research; $\mathrm{GC}, \mathrm{AC}$, manuscript writing; GC, AC, GR, manuscript conception; GC, PP, DB, AC; GR, critical revisions.

Conflict of interest: the authors declare no potential conflict of interest.

Received for publication: 14 April 2020.

Revision received: 21 April 2020.

Accepted for publication: 23 April 2020

This work is licensed under a Creative Commons Attribution-NonCommercial 4.0 International License (CC BY-NC 4.0).

${ }^{\circ}$ Copyright: the Author(s), 2020

Licensee PAGEPress, Italy

Geriatric Care 2020; 6:9029

doi:10.4081/gc.2020.9029

adaptive and innate immunity. ${ }^{10,11}$ Many are the alterations like: thymic involution, a decline of number naïve T-cells ${ }^{12}$ and of progenitor B-cells, ${ }^{13,14}$ a reduced expression of MHC class II on macrophages..$^{15}$ An important immunosuppressive status was also identified in chronic renal disease patients: i) decreased granulocyte and monocyte/macrophage phagocytic function; ${ }^{16}$ ii) defective antigen presenting capacity of antigen presenting cells; ${ }^{17}$ iii) depletion of the antigen presenting dendritic cells; ${ }^{18}$ iv) reduced numbers and antibody producing capacity of B lymphocyte; ${ }^{19} \mathrm{v}$ ) depletion of naïve and central memory $\mathrm{CD}^{+}$and $\mathrm{CD} 8^{+} \mathrm{T}$ lymphocyte; ${ }^{20}$ vi) impaired cell-mediated immunity. ${ }^{21,22}$ For all these reasons, old patients with chronic renal disease have to strictly respect indications from Ministry of Health and from Nephrological Scientific Societies for the prevention of COVID-19. Two host receptors have been proposed for COVID-19 attack to pneumocyte: CD26, also known as dipeptidyl-peptidase IV (DPP4) and ACE-2 (angiotensin-converting enzyme 2). ${ }^{23,24}$ For this reason, drug targeting these two receptors: DPP-4 inhibitors and angiotensin-receptor blockers (ARBs) were involved in recent discussions. Most patients affected by chronic renal disease are treated with ACE inhibitors (ACE-I) and angiotensin-receptor blockers (ARBs). Several studies have shown that ARBs and 
ACE-I increase ACE2 expression in the kidney and the heart. ${ }^{25-27}$ It is probably but not demonstrated that these classes of antihypertensive drugs can increase ACE2, that is the receptor for COVID-19, also in alveolar cells. It had been speculated that the use of these drugs could predispose patients to increased infection and more severe illness but really some studies suggest that ACE2 is protective in lung injury during coronavirus infection..$^{26,28}$ The nephrology community interrogated whether or not discontinuing ARBs and ACE-I in COVID-19 patients as long as the official statements by the European Society of Hypertension (ESH) and the European Society of Cardiology (ESC) has recommend that treatment should be as conservative as possible in patients at risk for COVID-19 or in those already diagnosed with COVID-19. ${ }^{29,30}$ Additionally, ARBs also associated with decreased mortality in patients with pneumonia. ${ }^{31}$ In this context, there is another very important, recent observation that ACE2 receptor abundance decreases in the elderly in all tissues. Prospective studies will be required to evaluate whether ARBs may have a therapeutic potential also in COVID-19 patients..$^{32}$

\section{Dialysis patients and COVID-19}

Dialysis patients are an aged population burdened with considerable comorbidities and with a high prevalence of frailty detected with geriatric tools of 3 times respect to individuals with normal renal function. They are often affected by heart failure, coronary artery disease, valvopathy, hypertension, diabetes Mellitus, respiratory problems (i.e. chronic obstructive pulmonary disease) which exposes them to a high risk of mortality if they contract acute lung disease. ${ }^{33-36}$ The dialysis patient infected with COVID-19 is of complex management by the healthcare provider. Fever is often absent due to uremic immunodepression and each patient is at high risk for other patients and health care staff. Transmissibility is made possible by the fact that they are dialyzed in a single environment, with difficulty in sanitizing between one shift and another. In addition, the pervasive prevalence of cognitive dysfunction $^{37}$ in uremic population make difficult social distancing provisions. According to a report from the Hemodialysis Centre of the University Hospital of Wuhan, ${ }^{38}$ in the period from January 14, 2020, date of the first confirmed case, to February 17, date of extinction of the epidemic in the centre, have occurred: 37 cases out of 230 patients on hemodialysis $(16 \%)$; 4 cases out of 33 operators $(12 \%)$ diagnosed with COVID-19. The presumed causes of death of seven patients were not directly related to pneumonia, but due to cardiovascular and cerebrovascular diseases. The two clear measures effective in limiting the internal epidemic until its extinction were: i) increase of prevention and protection measures for patients and staff of the centre; ii) universal screening of patients and staff at the centre for the rapid isolation and redistribution of patients. ${ }^{39}$

On February 27, 2020, the Italian Society of Nephrology, illustrated a protocol for the management of dialysis patients according to the cases, ${ }^{40}$ although all patients must thoroughly wash their hands and arm of the artero-venous fistula and disinfect the attachment points before the attack: i) in absence of disease manifestations, they must wear the surgical mask from when they arrive to when they leave; ii) patient arriving on dialysis with fever or infectious airway manifestations, must be evaluated by the specialist infectivologist to establish swabbing indications. Pending the outcome of the nose-pharyngeal swab, the patient should be hospitalized and dialyzed in a room suitable for contumacy with safety devices for health personnel (FFP2 mask, hair cap, water-repellent gown with long sleeves, eye protection, gloves). If the result of the swab is positive, the use of headgear, disposable gown in waterproof TNT, goggles, visor, FFP3 mask, over-shoes, gloves is available for healthcare personnel; iii) In case of respiratory failure and fever, the patient will be brought to the attention of resuscitators; iv) patients on peritoneal dialysis should be managed at home as far as possible.

\section{Transplanted renal patients and COVID-19}

The age of kidney transplant patients has increased over the past 20 to 25 years. ${ }^{41}$ The number of transplants performed annually among patients aged $\geq 65$ years has more than tripled between 1998 and 2016. ${ }^{42}$ These patients are at major risk of COVID-19 infection and complications because of the intake of immuno-suppressed drugs that make the immune system ineffective even more. For this reason, it is advisable to reduce hospital access to a minimum agreeing with the referral center, if possible, online visits.

\section{Acute renal injury and COVID-19}

Kidney was not identified as a direct target of coronavirus infection but some findings reported possible subsequent effects also on renal parenchyma with acute kidney injury evolution. Acute kidney injury caused by coronavirus infection is not rare. In literature, in previous reports of SARS and Middle East respiratory syndrome coronavirus infections, acute kidney injury (AKI) developed in $5 \%$ to $15 \%$ cases and carried a high $(60 \%$ $90 \%)$ mortality rate. Recently reports suggested a lower incidence $(3 \%-9 \%)$ of AKI in those with COVID-19 infection. ${ }^{43}$ Lately, Guan et al. described that the incidence of AKI was $0.5 \%$ in 1099 patients with novel coronavirus pneumonia, and in 173 critically ill patients, AKI arose in 5 patients $(2.9 \%){ }^{44}$ Cheng et al. displayed an incidence of AKI in 710 consecutive COVID-19 patients in a single-centre of $3.2 \%$. The exact incidence of AKI remains to be confirmed with larger sample size in the future. ${ }^{45}$ The acute kidney injury due to Coronavirus infection is mainly manifested as acute tubular necrosis, but the precise responsible mechanism is still not known. It may be due to a cytopathic direct effect of virus, or indirectly to sepsis and massive activation of the immune system with extreme release of cytokines, the so called cytokine storm syndrome, hypoxemia, rhabdomyolysis and renal hypoperfusion..$^{22,43}$

Dipeptidyl peptidase and angiotensin converting enzyme represents bindings sites for SARS-CoV-2 and are also located on renal cells. ${ }^{43}$ Urinary abnormalities (albuminuria and proteinuria) are found with a relative high incidence up to percentages of $34-63 \%$. On renal imaging with CT it was showed a reduced density characteristic of phlogistic evolutions. ${ }^{46}$

Extracorporeal therapies such as hemoperfusion or hemofiltration could be used to support different organs in a multiple organ dysfunction condition. Heart, lungs, kidneys, and liver can be partially replaced or at least sustained. The concept of ECOS (extracorporeal organ support) includes different types of circuits, different types of devices and filters which allow the extraction and the purification of blood. It was demonstrated that blood purification removes cytokines and improves hemodynamic and oxygenation. For this reason it could be used in patients with AKI and inflammatory storm. ${ }^{47}$ In patients in Intensive Care Units (ICUs) with complicated COVID-19 syndromes a significant improvement has been achieved with the use of hemoperfusion with cartridges containing highly biocompatible sorbents and microporous resins. ${ }^{48}$ Adsorption can be applied both alone and in combination with other blood purification techniques. ${ }^{49}$ These therapies improve the extreme release of cytokines and have a benefit in terms of organ function and hemodynamic support. Cartridges are divided in selective (e.g. polymyxin B hemoperfusion PMX HP) and 
non-selective types (Cytosorb ${ }^{\circledR}$ and HA330HA resin Jafron HA). The HA330-HA adsorbent inside the cartridges adsorbs excessive inflammatory factors and oxidative metabolites in the blood. It down-regulates the intensity of inflammatory response (in particular IL-6 amount) and restore the body's immunity. Moreover, it improves hemodynamic and respiratory parameters, reduce intensive care unit length of stay and ICU mortality. Another device is the Cytosorb $\AA$ that is an equally non selective extracorporeal cytokine absorber. All these cartridges could be used alone or associated with a conventional continuous veno-venous hemofiltration/hemodiafiltration circuit. ${ }^{50}$

\section{Renal implications of pharmacotherapy and COVID-19}

Drugs more used to fight COVID-19 infection were remdesivir, chloroquine /hydroxychloroquine, lopinavir/ritonavir, darunavir/ritonavir, darunavir/cobicistat, tocilizumab. Most drugs demonstrated a good renal tolerability while others need dose adjustments.

\section{Remdesivir}

Remdesivir is a nucleotide analogue that seems to have activity against COVID19, as well as against SARS and MERS. It is incorporated in the nascent viral RNA chain, resulting in its premature termination. The impact remains unknown even if it proves to be active in reducing viral load and lung function. Two trials are currently underway in China on the use of remdesivir in COVID-19. No renal function adjustment is required. ${ }^{7,51-54}$

\section{Chloroquine/hydroxychloroquine}

Chloroquine/hydroxychloroquine belong to the quinolone family both seem to inhibit the viral activity of the coronavirus in vitro, with higher potency for hydroxychloroquine. They seem to be able to exert their effect by increasing the endosomal $\mathrm{pH}$ necessary for virus-host cell fusion. Chloroquine appears to interfere with the glycosylation of SARS cell receptors. The use of these drugs in COVID-19 is associated with improved patient outcome. The administration of $500 \mathrm{mg}$ chloroquine BID for 10 days, or hydroxychloroquine $200 \mathrm{mg}$ BID for 10 days is recommended. Hydroxychloroquine needs adjustment for renal function: $200 \mathrm{mg} \times 2 /$ day if eGFR $>30$ $\mathrm{mL} / \mathrm{min} ; 200 \mathrm{mg} /$ day if $15<\mathrm{eGFR}<30$ $\mathrm{mL} / \mathrm{min} ; 200 \mathrm{mg}$ every other day if $<15$ $\mathrm{mL} / \mathrm{min}$ (or in 3-weekly or bi-weekly dialysis). Chloroquine is partially excreted renal and therefore a reduction of the dosage in renal failure should be made but there are no precise determinations. It is contraindicated if eGFR $<10 \mathrm{~mL} / \mathrm{min}^{55-62}$

\section{Lopinavir/ritonavir}

Lopinavir/ritonavir is known secondgeneration antiretroviral that inhibits HIV protease, is effective in vitro against SARS and in animal studies against MERS. The use has been described in several cases, reducing the coronavirus-19 charge rapidly in association with ribavirin. No adjustment for renal function is necessary. ${ }^{63-65}$

\section{Darunavir/ritonavir and darunavir/cobicistat}

Daruravir is a third generation antiretroviral that inhibits HIV viral protease. It demonstrates potency in viral suppression and increased tolerance in lopinavir/ritonavir, although the evidence in COVID-19 is limited. However, if lopinavir/ritonavir is not available, its use is recommended at darunavir/ritonavir $800+100 \mathrm{mg} / \mathrm{day}$ or darunavir/cobicistat $800+150 \mathrm{mg} /$ day. No adjustment is required for renal function. ${ }^{66}$

\section{Tocilizumab}

Tocilizumab has been included for a few days in the more severe treatments of COVID-19 as an IL-6 inhibitor. It is indicated in the BCRSS (Brescia-COVID Respiratory Severity Scale (BCRSS)/Algorithm) score $>=3$, in the presence of high levels of IL- 6 $(>40 \mathrm{pg} \%)$ or alternatively high levels of Ddimer and/or PCR and/or ferritin and/or fibrinogen, progressively increasing. It is contraindicated in age $<18$ years; if ALT/AST have values 5 times higher than normal levels; neutrophils $<500$ cell $/ \mathrm{mmc}$; PLT $<50.000$ cell/mmc; sepsis from other non-COVID-19 pathogens; complicated diverticulitis or intestinal perforation; ongoing skin infection; antirejection immunosuppressive therapy. A scheme with a maximum of 3 infusions is proposed at a dosage of $8 \mathrm{mg} / \mathrm{kg}$ of body weight (maximum dosage for infusion 800 $\mathrm{mg}$ ), with second infusion at a distance of 8$12 \mathrm{~h}$ from the first and third infusion at a distance of 16-24 $\mathrm{h}$ (if the clinical response is partial or incomplete). Tocilizumab should be combined with steroid and/or antiviral treatment. Dose adjustment for renal function is not necessary. ${ }^{67}$

\section{Conclusions}

COVID-19 is the new emergency in public health. It represents a big risk for elderly patients and in particular for those with longlasting renal disease. Since little is known about optimal therapy and we are a long way from a possible vaccine, the most effective strategy for controlling this infection is still the prevention. It is necessary that all the Nephrology Units and Dialysis in strict collaboration with geriatricians have a precise protocol of action for the management of patients. It should be preferable when possible an online visit and for patients that have to go to hospital, it is necessary ensuring pretriage and triage with temperature measurement. When there is a suspected COVID-19 case should be immediately isolated and subjected to a nasopharyngeal research for SARS-CoV-2. In this way, it will be possible limiting the diffusion of the virus to other patients and to the medical staff that can be a dangerous carrier.

\section{References}

1. Fried LP, Tangen CM, Walston J, et al.; Cardiovascular Health Study Collaborative Research G. Frailty in older adults: evidence for a phenotype. J Gerontol A Biol Sci Med Sci 2001;56:M146-56.

2. Gralinski LE, Menachery VD. Return of the coronavirus: 2019-nCoV. Viruses 2020;12. [Epub ahead of print].

3. Weston S, Frieman MB. COVID-19: Knowns, Unknowns, and Questions. mSphere 2020;5. [Epub ahead of print].

4. Kolifarhood G, Aghaali M, Mozafar Saadati H, et al. Epidemiological and Clinical Aspects of COVID-19; a Narrative Review. Arch Acad Emerg Med. 2020;8:e41.

5. Wu Z, McGoogan JM. Characteristics of and Important Lessons From the Coronavirus Disease 2019 (COVID-19) Outbreak in China: Summary of a Report of 72314 Cases From the Chinese Center for Disease Control and Prevention. JAMA 2020. [Epub ahead of print].

6. Grasselli G, Pesenti A, Cecconi M. Critical Care Utilization for the COVID-19 Outbreak in Lombardy, Italy: Early Experience and Forecast During an Emergency Response. JAMA 2020. [Epub ahead of print].

7. Cai J, Xu J, Lin D, et al. A Case Series of children with 2019 novel coronavirus infection: clinical and epidemiological features. Clin Infect Dis 2020. [Epub ahead of print].

8. Polidori MC, Maggi S, Mattace-Raso F, Pilotto A. The unavoidable costs of frailty: a geriatric perspective in the time of COVID-19. Geriatric Care 2020;6:8989.

9. Esposito C, Plati A, Mazzullo T, et al. 
Renal function and functional reserve in healthy elderly individuals. J Nephrol 2007;20:617-25.

10. Fulop T, Larbi A, Witkowski JM, et al. Immunosenescence and cancer. Crit Rev Oncog 2013;18:489-513.

11. Weinberger B, Grubeck-Loebenstein B. Vaccines for the elderly. Clin Microbiol Infect 2012;18:100-8.

12. Lynch HE, Goldberg GL, Chidgey A, et al. Thymic involution and immune reconstitution. Trends Immunol 2009; 30:366-73.

13. Larbi A, Cabreiro F, Zelba $\mathrm{H}$, et al. Reduced oxygen tension results in reduced human $\mathrm{T}$ cell proliferation and increased intracellular oxidative damage and susceptibility to apoptosis upon activation. Free Radic Biol Med 2010; 48:26-34.

14. Coppolino G, Leonardi G, Andreucci M, Bolignano D. Oxidative Stress and Kidney Function: A Brief Update. Curr Pharm Des 2018;24:4794-9.

15. Herrero C, Marques L, Lloberas J, Celada A. IFN-gamma-dependent transcription of MHC class II IA is impaired in macrophages from aged mice. J Clin Invest 2001;107:485-93.

16. Alexiewicz JM, Smogorzewski M, Fadda GZ, Massry SG. Impaired phagocytosis in dialysis patients: studies on mechanisms. Am J Nephrol 1991;11: 102-11.

17. Girndt M, Sester M, Sester U, et al. Molecular aspects of T- and B-cell function in uremia. Kidney Int Suppl 2001;78:S206-11.

18. Agrawal S, Gollapudi P, Elahimehr R, et al. Effects of end-stage renal disease and haemodialysis on dendritic cell subsets and basal and LPS-stimulated cytokine production. Nephrol Dial Transplant 2010;25:737-46.

19. Pahl MV, Gollapudi S, Sepassi L, et al. Effect of end-stage renal disease on Blymphocyte subpopulations, IL-7, BAFF and BAFF receptor expression. Nephrol Dial Transplant 2010;25:205-12.

20. Matsumoto Y, Shinzato T, Amano I, et al. Relationship between susceptibility to apoptosis and Fas expression in peripheral blood T cells from uremic patients: a possible mechanism for lymphopenia in chronic renal failure. Biochem Biophys Res Commun 1995;215:98-105.

21. Moser B, Roth G, Brunner M, et al. Aberrant $\mathrm{T}$ cell activation and heightened apoptotic turnover in end-stage renal failure patients: a comparative evaluation between non-dialysis, haemodialysis, and peritoneal dialysis. Biochem Biophys Res Commun 2003;308:581-5.
22. Leporini C, Pisano A, Russo E, et al. Effect of pentoxifylline on renal outcomes in chronic kidney disease patients: A systematic review and meta-analysis. Pharmacol Res 2016;107:315-32.

23. Coppolino G, Leporini C, Rivoli L, et al. Exploring the effects of DPP-4 inhibitors on the kidney from the bench to clinical trials. Pharmacol Res 2018; 129:274-94.

24. Sargiacomo C, Sotgia F, Lisanti MP. COVID-19 and chronological aging: senolytics and other anti-aging drugs for the treatment or prevention of corona virus infection? Aging (Albany NY) 2020. [Epub ahead of print].

25. Jessup JA, Gallagher PE, Averill DB, et al. Effect of angiotensin II blockade on a new congenic model of hypertension derived from transgenic Ren-2 rats. Am J Physiol Heart Circ Physiol 2006;291: H2166-72.

26. Bolignano D, Pisano A, Coppolino G. The Dark Side of Blocking RAS in Diabetic Patients with Incipient or Manifested Nephropathy. Exp Clin Endocrinol Diabetes 2016;124:350-60.

27. Simeoni M, Nicotera R, Colao M, et al. Direct inhibition of plasmatic renin activity with aliskiren: a promising but under-investigated therapeutic option for non-diabetic glomerulonephritis. Int Urol Nephrol 2016;48:229-37.

28. Fang L, Karakiulakis G, Roth M. Are patients with hypertension and diabetes mellitus at increased risk for COVID-19 infection? Lancet Respir Med 2020; $8: \mathrm{e} 21$

29. Gheblawi M, Wang K, Viveiros A, et al. Angiotensin Converting Enzyme 2: SARS-CoV-2 Receptor and Regulator of the Renin-Angiotensin System. Circ Res 2020. [Epub ahead of print].

30. Iaccarino G, Borghi C, Cicero AFG, et al. Renin-Angiotensin System Inhibition in Cardiovascular Patients at the Time of COVID19: Much Ado for Nothing? A Statement of Activity from the Directors of the Board and the Scientific Directors of the Italian Society of Hypertension. High Blood Press Cardiovasc Prev 2020. [Epub ahead of print].

31. Imai $Y$, Kuba $K$, Rao $S$, et al. Angiotensin-converting enzyme 2 protects from severe acute lung failure. Nature 2005;436:112-6.

32. Kickbusch I, Leung G. Response to the emerging novel coronavirus outbreak. BMJ 2020;368:m406.

33. Saha M, Allon M. Diagnosis, Treatment, and Prevention of Hemodialysis Emergencies. Clin J Am Soc Nephrol 2017;12:357-69.

34. Rodriguez-Morales AJ, Cardona-
Ospina JA, Gutierrez-Ocampo E, et al.; Latin American Network of Coronavirus Disease C-REahwlo. Clinical, laboratory and imaging features of COVID-19: A systematic review and meta-analysis. Travel Med Infect Dis 2020:101623.

35. Yang J, Zheng Y, Gou X, et al. Prevalence of comorbidities in the novel Wuhan coronavirus (COVID-19) infection: a systematic review and meta-analysis. Int J Infect Dis 2020. [Epub ahead of print].

36. Coppolino G, Lucisano G, Bolignano D, Buemi M. Acute cardiovascular complications of hemodialysis. Minerva Urol Nefrol 2010;62:67-80.

37. Coppolino G, Bolignano D, Gareri P, et al. Kidney function and cognitive decline in frail elderly: two faces of the same coin? Int Urol Nephrol 2018;50:1505-10.

38. Ma Y, Diao B, Lv X, et al. 2019 novel coronavirus disease in hemodialysis (HD) patients: Report from one HD center in Wuhan, China. medRxiv 2020:2020.02.24.20027201. [Epub ahead of print].

39. Onder G, Rezza G, Brusaferro S. CaseFatality Rate and Characteristics of Patients Dying in Relation to COVID19 in Italy. JAMA 2020. [Epub ahead of print].

40. Alberici F, Del Barba E, Manenti C, et al. [Gestione del paziente in dialisi e con trapianto di rene in corso di infezione da coronavirus Covid-19]. G Ital Nefrol 2020. [Epub ahead of print].

41. Hart A, Smith JM, Skeans MA, et al. OPTN/SRTR 2016 Annual Data Report: Kidney. Am J Transplant 2018; 18:18-113.

42. Schaeffner ES, Rose C, Gill JS. Access to kidney transplantation among the elderly in the United States: a glass half full, not half empty. Clin J Am Soc Nephrol 2010;5:2109-14.

43. Naicker S, Yang CW, Hwang SJ, et al. The Novel Coronavirus 2019 epidemic and kidneys. Kidney Int 2020. [Epub ahead of print].

44. Deng Y, Liu W, Liu K, et al. Clinical characteristics of fatal and recovered cases of coronavirus disease 2019 (COVID-19) in Wuhan, China: a retrospective study. Chin Med J (Engl) 2020. [Epub ahead of print].

45. Cheng Y, Luo R, Wang K, et al. Kidney impairment is associated with in-hospital death of COVID-19 patients. medRxiv 2020:2020.02.18.20023242. [Epub ahead of print].

46. Zhang L, Shen FM, Chen F, Lin Z. Origin and evolution of the 2019 novel 
coronavirus. Clin Infect Dis 2020. [Epub ahead of print].

47. Datzmann T, Trager K. Extracorporeal membrane oxygenation and cytokine adsorption. J Thorac Dis 2018;10:S653S660.

48. Ronco C, Reis T, De Rosa S. Coronavirus Epidemic and Extracorporeal Therapies in Intensive Care: si vis pacem para bellum. Blood Purif 2020:1-4.

49. Ankawi G, Fan W, Pomare Montin D, et al. A New Series of Sorbent Devices for Multiple Clinical Purposes: Current Evidence and Future Directions. Blood Purif 2019;47:94-100.

50. Honore PM, De Bels D, Barreto Gutierrez L, Spapen HD. Hemoadsorption therapy in the critically ill: solid base but clinical haze. Ann Intensive Care 2019;9:22.

51. Agostini ML, Andres EL, Sims AC, et al. Coronavirus Susceptibility to the Antiviral Remdesivir (GS-5734) Is Mediated by the Viral Polymerase and the Proofreading Exoribonuclease. mBio 2018;9.

52. Lai CC, Shih TP, Ko WC, et al. Severe acute respiratory syndrome coronavirus 2 (SARS-CoV-2) and coronavirus disease-2019 (COVID-19): The epidemic and the challenges. Int $\mathrm{J}$ Antimicrob Agents 2020;55:105924.

53. Sheahan TP, Sims AC, Leist SR, et al. Comparative therapeutic efficacy of remdesivir and combination lopinavir, ritonavir, and interferon beta against
MERS-CoV. Nat Commun 2020; 11:222.

54. Dong L, Hu S, Gao J. Discovering drugs to treat coronavirus disease 2019 (COVID-19). Drug Discov Ther 2020;14:58-60.

55. Vincent MJ, Bergeron E, Benjannet S, et al. Chloroquine is a potent inhibitor of SARS coronavirus infection and spread. Virol J 2005;2:69.

56. Touret F, de Lamballerie X. Of chloroquine and COVID-19. Antiviral Res 2020;177:104762.

57. Mascolo A, Berrino PM, Gareri P, et al. Neuropsychiatric clinical manifestations in elderly patients treated with hydroxychloroquine: a review article. Inflammopharmacology 2018;26:1141-9.

58. Colson P, Rolain JM, Raoult D. Chloroquine for the 2019 novel coronavirus SARS-CoV-2. Int J Antimicrob Agents 2020;55:105923.

59. Multicenter CollaborationGroup of Department of Technology of Guangdong and Health Commission of Guangdong Province for chloroquine in the treatment of novel coronavirus. [Expert consensus on chloroquine phosphate for the treatment of novel coronavirus pneumonia]. Zhonghua Jie $\mathrm{He}$ He Hu Xi Za Zhi 2020;43:185-8.

60. Yao X, Ye F, Zhang M, et al. In Vitro Antiviral Activity and Projection of Optimized Dosing Design of Hydroxychloroquine for the Treatment of Severe Acute Respiratory Syndrome Coronavirus 2 (SARS-CoV-2). Clin
Infect Dis 2020. [Epub ahead of print].

61. Sahraei Z, Shabani M, Shokouhi S, Saffaei A. Aminoquinolines against coronavirus disease 2019 (COVID-19): chloroquine or hydroxychloroquine. Int J Antimicrob Agents 2020:105945.

62. Manzo C, Gareri P, Castagna A. Psychomotor Agitation Following Treatment with Hydroxychloroquine. Drug Saf Case Rep 2017;4:6.

63. Yao TT, Qian JD, Zhu WY, et al. A systematic review of lopinavir therapy for SARS coronavirus and MERS coronavirus-A possible reference for coronavirus disease-19 treatment option. J Med Virol 2020. [Epub ahead of print].

64. Lim J, Jeon S, Shin HY, et al. The Author's Response: Case of the Index Patient Who Caused Tertiary Transmission of Coronavirus Disease 2019 in Korea: the Application of Lopinavir/Ritonavir for the Treatment of COVID-19 Pneumonia Monitored by Quantitative RT-PCR. J Korean Med Sci 2020;35:e89.

65. Totura AL, Bavari S. Broad-spectrum coronavirus antiviral drug discovery. Expert Opin Drug Discov 2019;14:397412.

66. Cunningham AC, Goh HP, Koh D. Treatment of COVID-19: old tricks for new challenges. Crit Care 2020;24:91.

67. Zhou M, Zhang X, Qu J. Coronavirus disease 2019 (COVID-19): a clinical update. Front Med 2020. [Epub ahead of print]. 